\title{
Programming DNA-based Systems through Effective Molarity Enforced by Biomolecular Confinement
}

Marianna Rossetti, ${ }^{+}$Alessandro Bertucci, ${ }^{+}$Tania Patiño, Lorena Baranda, Alessandro Porchetta*
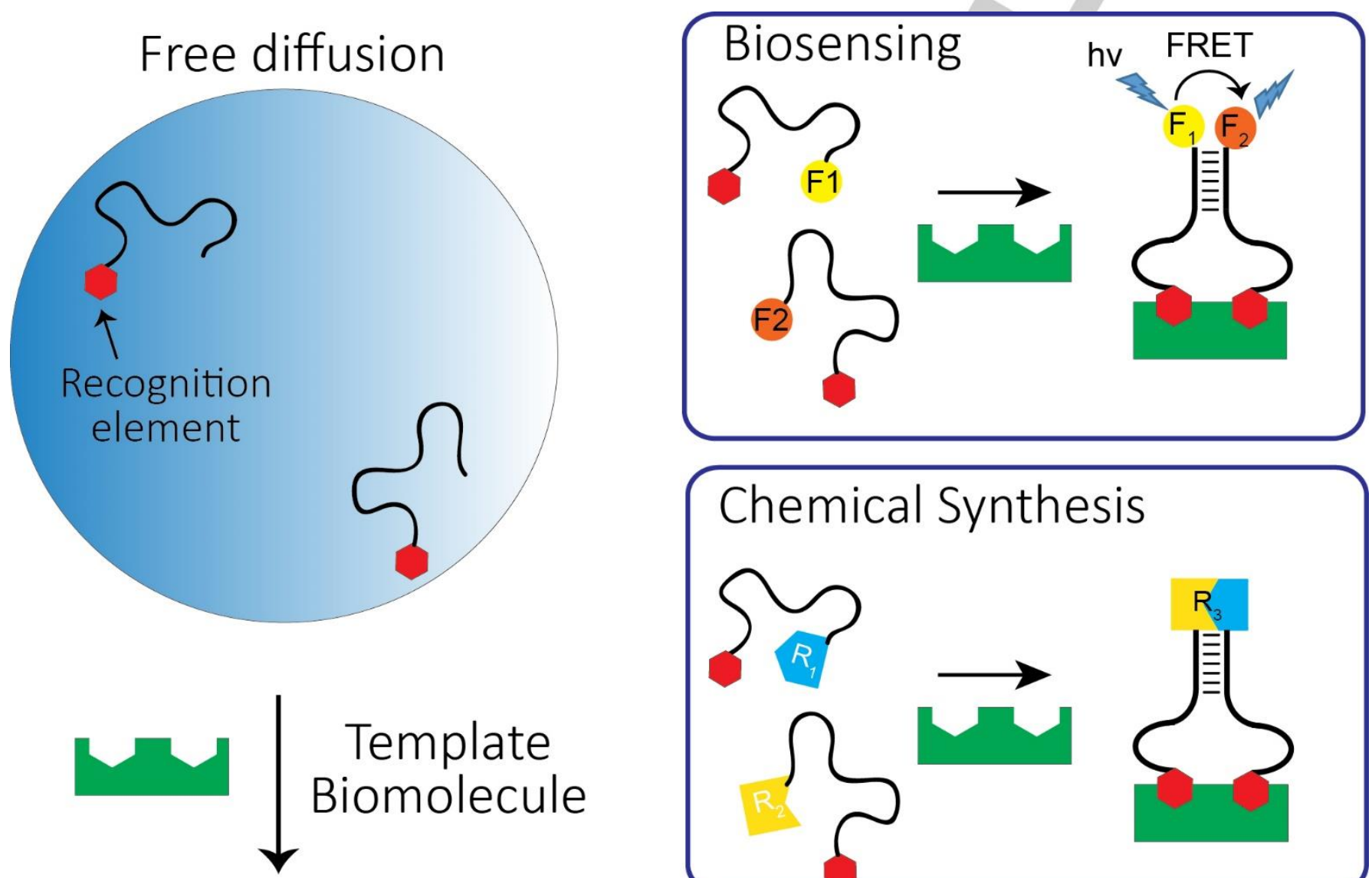

\section{Chemical Synthesis}
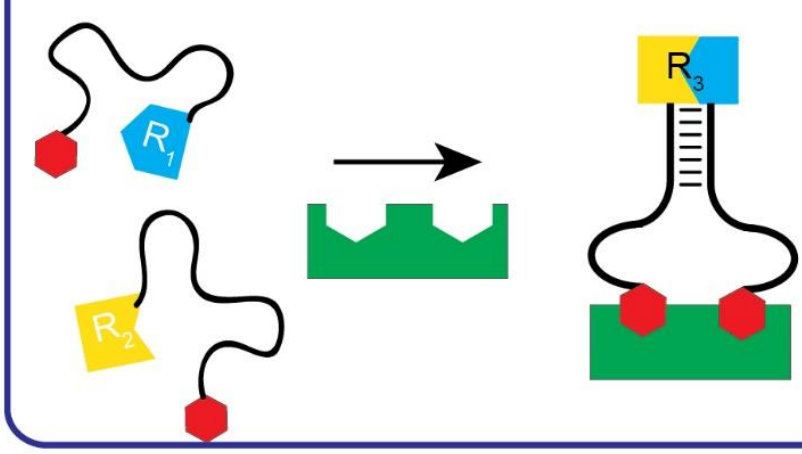

Catalysis
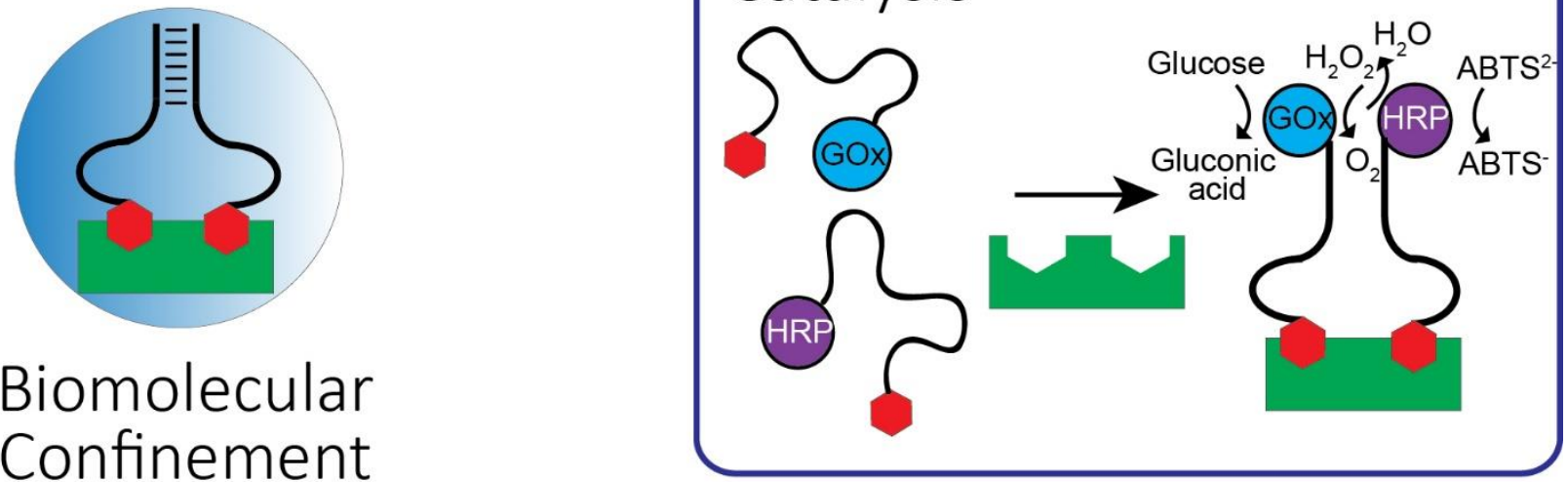

Biomolecular Confinement

M. Rossetti, A. Bertucci, T. Patiño, L. Baranda, A. Porchetta

Via della Ricerca Scientifica, 00133 Rome, Italy

E-mail: alessandro.porchetta@uniroma2.it

[+] These authors contributed equally. 
Abstract: The fundamental concept of effective molarity is observed in a variety of biological processes such as protein compartmentalization within organelles, membrane localization and signaling paths. To control molecular encountering and promote effective interactions, Nature places biomolecules in specific sites inside the cell in order to generate a high, localized concentration different from the bulk concentration. Inspired by this mechanism, scientists have artificially recreated in the lab the same strategy to actuate and control artificial DNA-based functional systems. Here we discuss how harnessing effective molarity has led to the development of a number of proximity-induced strategies with applications ranging from DNA-templated organic chemistry and catalysis, to biosensing and protein-supported DNA assembly.

\section{Introduction}

The predictable hybridization between complementary base pairs that underlies the self-assembly of deoxyribonucleic acids (DNAs) lays the chemical foundation for engineering highly structured materials, ${ }^{[1-4]}$ dynamic nanodevices ${ }^{[5-14]}$ and complex reaction networks for molecular computation. ${ }^{[15-17]}$ Functional DNA nanotechnology has greatly benefited from the extensive use of programmable strand displacement reactions upholding the design of stimuli-responsive DNA switches, ${ }^{[18-21]}$ enzyme-free catalytic systems, ${ }^{[22-26]}$ or molecular computers. ${ }^{[27-29]}$ In addition, DNA-based dynamic networks have been designed to process information following cell-inspired paths that mimic more complex natural molecular mechanisms. ${ }^{[30,31]}$

Biological processes are underpinned by much more than a mere combination of uniformly distributed molecules reacting with one another in a diffusive regime. In cells, functionality strongly depends on the proper spatial and temporal synchronization of biochemical reactions. ${ }^{[32,33]}$ In particular, compartmentalization and colocalization are pervasive mechanisms that regulate a variety of cellular processes in living systems. ${ }^{[34,35]}$ For instance, many ordinary cellular activities including signaling and information storage are performed inside heterogeneous $\mathrm{fL}$-scale compartments. ${ }^{[36]}$ Nature also employs fundamental "forces" as electrostatic or hydrophobic interactions to promote molecular encountering through spatial co-localization on molecular scaffolds. As an example, biochemical processes such as transcription and translation generally take advantage of the presence of scaffold proteins that can provide a severalthousand-fold enhancement of enzymatic reaction rates. ${ }^{[37]}$ As a result, the localized concentration, namely effective molarity, may differ from the bulk solution by several orders of magnitude, which generally leads to a drastic increase of the encounter rates and of the binding affinity between confined species. The concept of effective molarity has been around in the field of organic synthesis for decades. The impact of intramolecular interactions on reaction rates, equilibria, and mechanisms of cyclization of chain molecules was already under investigation in the early 1970 s. Colocalization of reactants influences intramolecular interactions generating a decrease of translational and rotational entropy that leads to a dramatic increase of the reaction rate. In some cases, the concentrations of the reactants needed to allow an intermolecular reaction to display the same rate of an analogous intramolecular reaction can be terribly high ( $\geq 100 \mathrm{M}){ }^{[38,39]}$
Inspired by naturally occurring mechanisms, scientists have then demonstrated that the same strategies can be artificially recreated and used in conjunction with programmable DNA assembly to actuate and control artificial DNA-based functional systems. Putting this concept into practice in DNA Nanotechnology has led to the development of many proximityinduced strategies with applications ranging from DNA-templated organic chemistry and catalysis to biosensing and proteinsupported DNA assembly. Additionally, DNA-directed effective molarity has emerged as a tool to study and probe complex biological mechanisms out of the cell environment. ${ }^{[40]}$ We believe that effective molarity-driven DNA-based systems will play an increasingly bigger role in aiding to gain fundamental insights into cellular processes, in supporting the rational design of synthetic biomimicry and in expanding the molecular toolbox in supramolecular chemistry. Here we highlight and discuss the utilization of biomolecular confinement and effective molarity as means to program and assemble functional systems in DNA nanotechnology.

\section{Assembling DNA on protein substrates}

The natural processes of biomolecular colocalization and spatial confinement underlie protein-protein interactions and their connected biological networks. ${ }^{[41]}$ Proximity-induced DNA assembly can be engineered to mirror this mechanism by engaging proteins as substrates upholding molecular encountering in a confined space. When DNA units are conjugated to specific affinity ligands, the interaction of these latter with multiple binding sites on a target protein allow the nucleic acid strands to be localized in a restricted volume, thus promoting their effective hybridization by boosting their encounter rate. ${ }^{[42]}$ In this way, the interacting protein serves as both a molecular trigger and a structural support. In a seminal work, Fredriksson et al. expressed the potential of this approach and developed a "proximity ligation" method for protein detection. ${ }^{[43]}$ The authors took advantage of the affinity of the platelet-derived growth factor B-chain (PDGF-BB) for a cognate DNA aptamer and designed a pair of aptamer-modified DNA probes that, when brought to proximity upon protein affinity binding, could efficiently hybridize with a third connector DNA, allowing for enzymatic ligation of the two probe ends and subsequent PCR-based amplification and detection of the ligation product. Proximity ligation has since then become a widespread tool for protein analysis. ${ }^{[44-46]}$ Through a protein-templated ligation reaction a DNA reporter sequence is formed, amplified and detected, following a translation process in which a target protein is associated to a precise DNA bar code. ${ }^{[47,48]}$

Biomolecular confinement can also be harnessed to control dynamic DNA-based reactions in a protein-templated manner. Le and coworkers put their spin on DNA strand displacement reactions and developed a binding-induced strategy in which, differently from the classical toehold-mediated mechanism, the release of an output DNA strand is triggered by a protein binding event accelerating the rate of DNA hybridization. ${ }^{[49]}$ It can be estimated that the effective local concentrations of the oligonucleotides involved in a binding-induced strand 
displacement undergo $\mathrm{a} \sim 6500$-fold enhancement upon their confinement in the target protein volume.

Marianna Rossetti is a post-doctoral researcher in the Chemistry Department of the University of Rome Tor Vergata. Her research interests include functional DNA nanotechnology, biosensors and drug release applications. Her post-doc fellowship is currently funded by the "Umberto Veronesi Foundation“.

Alessandro Bertucci is a former Marie Sklodowska-Curie Fellow and currently a Fondazione Umberto Veronesi Research Fellow at the Chemistry Department of the University of Rome Tor Vergata. His research interests lie in bio-supramolecular chemistry, hybrid materials and DNA nanotechnology for biomedical applications.

Tania Patiño is currently Marie Curie postdoctoral fellow at the Chemistry Department of the University of Rome Tor Vergata. Her research is focused on the development of enzyme-powered nanomachines and DNA nanotechnology for nanomedicine-related applications.
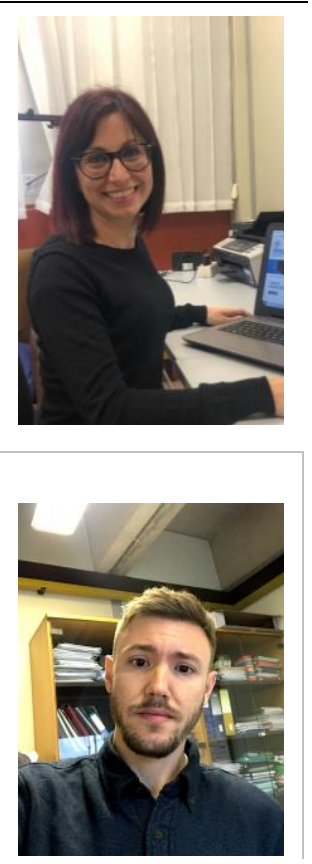

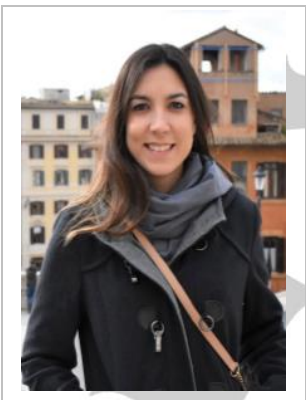

Lorena Baranda is a doctoral student in the Chemistry Department of the University of Rome Tor Vergata. Her PhD project, in the frame of the Marie-Curie ITN project DNARobotics, is focused on the control of DNAtemplated reactions by biomolecules for sensing and drug delivery applications. Her research is funded by the European Union's Horizon 2020 research and innovation programme.

Alessandro Porchetta is an assistant professor in the Department of Chemistry of the University of Rome Tor Vergata. He has been recently awarded the "European Young Chemist Award 2018" at the post-doctoral level. His research interests lay in the area of biomolecular engineering, particularly in nucleic acid systems for diagnostic applications.
Other factors, including the length of the DNA probes and the flexibility of spacer regions, are then deemed to add on the colocalization effect and determine the final rate of the DNA reaction. ${ }^{[50]}$ Of note, Zhang et al. used the binding-induced DNA strand displacement strategy in conjunction with a nanopore technology and performed amplification-free detection of a protein biomarker enabled by the electrical signal generated by the output DNA strand. ${ }^{[51]}$ Through a rational design of the interacting DNA modules, it is possible to implement the binding-induced strategy for constructing more complex DNA assemblies, such as threeway DNA junctions, ${ }^{[52,53]}$ and for controlling synthetic DNA circuits with protein-responsive activation (Fig. 1a). ${ }^{[54,55]}$ Colocalizationenabled DNA networks can also be deployed in vitro and utilized as tools to study and image receptor proteins on the cell surface. Liang et al. designed a proximity-induced DNA assembly to detect in real-time the dimerization of mesenchymal epithelial transition (Met) receptors by using aptamer-conjugated DNA probes (Fig. 1b). The formation of receptor dimers on the cell surface upon ligand stimulation causes the spatial colocalization of the bound DNA probes and their consequent efficient hybridization, which is used to initiate a signaling strand displacement reaction. ${ }^{[56]}$ While all the above examples demonstrate the potential of binding induced DNA assembly in the design of programmable biomimetic systems and technologies, a current, intrinsic limitation yet to be addressed is the relatively short number of DNA aptamer ligands that are available to support such strategies. For this, we believe that further advancements in DNA and RNA aptamer discovery through SELEX will likely expand the nucleic acid-based toolbox of usable ligands for proximity-induced systems. More importantly, we envision that the use of peptide ligands in conjunction with chimera probes and higher-level modular designs will have an impact on the field by substantially increasing the number of target proteins that can be engaged in the process.

With regard to this, we note that sensing of cell surface proteins based on proximity-induced DNA assembly can also be achieved, for instance, by using DNA probes conjugated to specific antibodies as affinity ligands, which involves a somewhat double degree of molecular colocalization. ${ }^{[57,58]}$ Eventually, we would like to underline that the natural colocalization process can also be artificially recreated on man-made substrates. In this regard, Merkx and coworkers showed that the rate of DNA-based circuit operations can be greatly accelerated by using supramolecular polymers that provide anchoring handles for DNA spatial confinement. ${ }^{[59]}$

\section{Antibody-templated DNA systems}

In antibody-templated DNA systems, the confinement of DNA-based modules can be achieved by taking advantage of the characteristic $y$-shaped structure shared by all $\lg G$ and $\operatorname{lgE}$ antibodies, in which two identical antigen binding sites are distant approximately $10-12 \mathrm{~nm} \cdot{ }^{[60-62]}$ This spatial geometry allows the co-localization of two DNA-strands properly modified with a specific recognition element (i.e., antigen) in a confined volume, leading to an increase in their effective molarity. ${ }^{[63]}$ The enhanced local concentrations can in turn trigger molecular interactions that would not occur in the absence of the antibody.

Merkx et al. demonstrated that antibodies are able to engage in multivalent interactions and form cyclic complexes with peptide- 
dsDNA conjugates that display 1 or 2 peptide ligands. ${ }^{[64]}$ The interaction between a bivalent peptide-dsDNA conjugate and an antibody is 500 -fold stronger than that of a monovalent peptide, which allows for effective blocking the antigen binding sites in a non-covalent manner.

One of the first applications based on this concept was reported by Heyduk et al. for the development of sensors towards antibodies and protein antigens. ${ }^{[65]}$ These sensors hinge on the use of two complementary DNA strands, each one labelled with a fluorophore to form a FRET couple and terminally conjugated with a specific antigen. The length of the two complementary portions is designed to be short enough to prevent hybridization in the absence of the target antibody. In the presence of this latter, instead, the local concentration of each of the two strands greatly increases due to the binding on the same antibody and leads to their annealing and thereby to the generation of a FRET signal. A systematic study of the impact of stem sequences in such molecular systems has been reported by Yan et al. ${ }^{[6]}$ However, systems based on the hybridization of two signalling antigentethered short complementary oligonucleotides present some restrictions, such as limited signal gains and nontrivial design of the sensing elements. In an attempt to overcome these potential drawbacks, Porchetta et al. reported a novel strategy based on the use of a reporter and an input module that in the presence of a target antibody are brought in close proximity and result in the generation of a fluorescence signal through the controlled opening of a molecular beacon (Fig. 1c). ${ }^{[67]}$

The proposed strategy shows several advantages, including an easy modular design that makes potentially possible to detect any $\lg G$ and $\lg E$ antibody, a rapid time of analysis $(<10$ $\mathrm{min}$ ), high signal gains with nanomolar limits of detection and the possibility of performing multiplex analysis by using different fluorophore/quencher pairs in an orthogonal way. In a follow-up work, a similar strategy was used to develop a competitive assay for the detection of small molecules. ${ }^{[68]}$
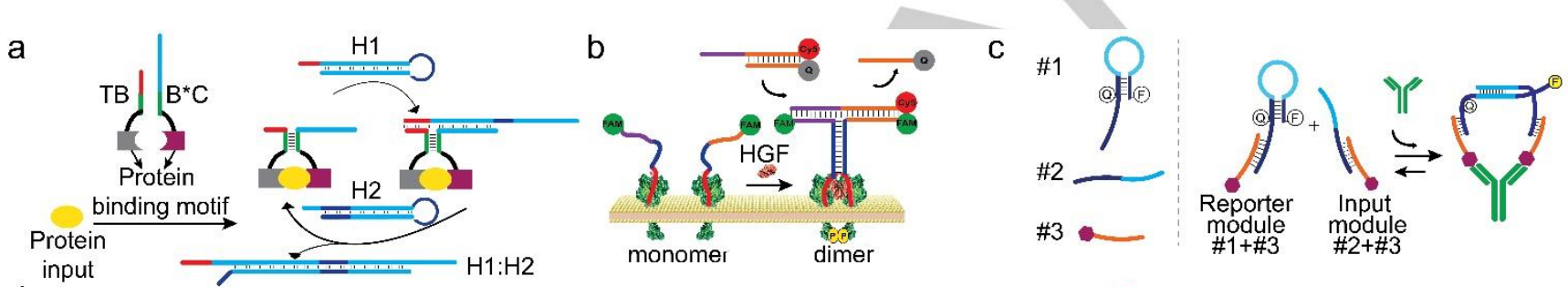

d

Base
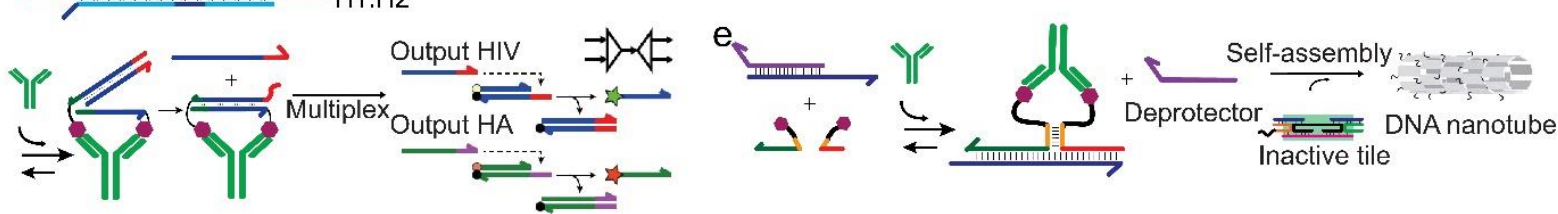

Figure 1. (a) Protein-responsive catalytic hairpin assembly ( $\mathrm{CHA})$. The catalytic process begins only when the input strand is formed as a protein-templated threeway junction. Adapted with permission from [54]. Copyright (2015) American Chemical Society. (b) Protein dimerization on the cell membrane by aptamer recognition and proximity-induced DNA Assembly. This strategy allows to detect in real-time the dimerization of mesenchymal epithelial transition (Met) receptors by using 40mer Met-binding DNA aptamers as interacting ligands. Adapted with permission from [56]. Copyright (2018) American Chemical Society. (c) Effective-molarity driven nucleic acid nanoswitch activation induced by clinically relevant target antibodies. The co-localization of the two modules on the same target antibody generates an increase in the local concentration that results in the opening of the nanoswitch and fluorescence emission. Adapted with permission from [67]. Copyright (2018) American Chemical Society. (d) DNA-based molecular circuits controlled by antibodies. Both base and invading strands are conjugated to 3'-end with the antibodyspecific peptide epitope. In the presence of the antibody, base and invading strands bind to the target antibody and their confinement induces the toehold exchange reaction. Adapted with permission from [71]. Copyright (2017) Springer Nature. (e) DNA self-assembly triggered by antibodies. The binding between the target antibody and the two antigen-conjugated split DNA input-strands induce the reconstitution of the full input strand that in turn activate toehold strand displacement reaction. The consequent release of the strand (i.e. deprotector) triggers self-assembling of DNA nanotube. Adapted with permission from [72]. Copyright (2019) Springer Nature.

Sensing of antibodies has also been achieved by reconstitution of a split fluorescent RNA aptamer. Bertucci et al. demonstrated that two fragments of a Spinach aptamer, each one conjugated to a same specific antigen, can be reassembled into the functional signaling structure utilizing a target antibody as biomolecular template. ${ }^{[69]}$ We note that the above methods did not employ any amplification steps, which can be of relevance in terms of simplicity and costs. Nevertheless, amplification strategies may be instead useful to significantly improve sensitivity and detection limits. Effort in this direction has been made by Li et al., who reported an antibody-responsive hybridization chain assembly in which the initiator DNA strand is generated only in the presence of a specific antibody. ${ }^{[70]}$

Besides analytical purposes, antibody-induced effective molarity can generate many other applications ranging from the construction of molecular circuits to the activation of DNA-based nanostructures. A general strategy to use antibodies as biomolecular inputs for DNA-based molecular circuitry was developed by Merkx and co-workers (Fig. 1d), ${ }^{[71]}$ who reported antibody-templated toehold-mediated strand exchange (ATSE) reactions. In their paper, the authors investigated several thermodynamic and kinetic parameters influencing the process and proposed a comprehensive theoretical model in which the efficiency of ATSE reactions is a function of toehold length, antibody-epitope affinity and antibody/DNA concentration. Recently, the use of antibodies as inputs to control the assembly and disassembly of more complex DNA nanostructures has been reported by Ricci and co-workers. ${ }^{[72]}$ Here, the input strand of the toehold-mediated displacement reaction was split into two portions and each of these was equipped with a DNA tail containing a mutual complementary domain and a poly-thymine linker conjugated with a specific antigen. The binding between the 
target antibody and the two antigen-conjugated DNA strands leads to the formation of the active input strand that can initiate the toehold-mediated strand displacement reaction. Furthermore, the displaced strand can be utilized as either a "deprotector" or an "invader" strand" to regulate the self-assembly or disassembly of DNA nanotubes, respectively (Fig. 1e).

\section{Chemical synthesis on DNA-based supports}

Right at the core of the cellular machinery lies one of the oldest examples of DNA-templated reactions, the process of DNA replication, in which an unwound DNA double helix serves as a template for the synthesis of the complementary product. ${ }^{[73]}$ This DNA-driven templating effect allows cells to selectively direct chemical reactions towards the formation of the desired product. Similarly, control over reactivity is a central concern for chemists when multiple species are present in the same solution. Taking inspiration from how nature directs and harmonizes chemical processes, researchers covalently linked reactants to complementary oligonucleotides, so as they substantially increase their effective concentration upon hybridization, which can trigger a reaction that would otherwise not occur at the initial concentration in solution. ${ }^{[74}$ The earliest examples of nonenzymatic ligations templated by DNA were reported by the groups of Naylor ${ }^{[75]}$ and Orge ${ }^{[76]}$ and focused on the formation of phosphodiesters, although low yields were obtained and only limited chemical strategies were employed. The range of reactions supported by this strategy was then expanded, which gave rise to the field of DNA-templated organic synthesis, ${ }^{[77]}$ with applications in sensing, ${ }^{[78]}$ drug delivery, ${ }^{[79]}$ programmed multistep synthesis, ${ }^{[80]}$ and chemical libraries. ${ }^{[81,82]}$

DNA-templated synthesis (DTS) persists as a powerful tool for nucleic acid sensing. The first auto-ligation reactions enabled the detection of single mismatches, although analytical instrumentations such as HPLC were needed downstream for product determination. ${ }^{[83]}$ To overcome this drawback, reactions that yield a measurable signal were employed, including FRET transfer ${ }^{[84]}$ and fluorogenic reactions ${ }^{\left[{ }^{85,86]}\right.}$ such as the formation of cyanine dyes (Fig. 2a). ${ }^{[87]}$ More recently, sensing enabled by DNA-templated strategies was achieved in much more complex matrices, as shown by the detection of microRNA targets in a live vertebrate by generating fluorogenic rhodamine ${ }^{[88]}$ or the detection of a single nucleotide deletion associated with resistance in a $\mathrm{H}$. pylori lysate by means of a fluorogenic cascade reaction. ${ }^{\left[{ }^{[9]}\right.}$ Additionally, when a secondary product is released from the templated reaction, the capability of the approach to be applied for drug delivery applications becomes evident. a

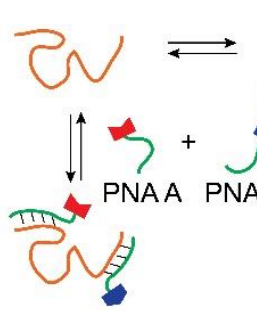

Not Fluorescent

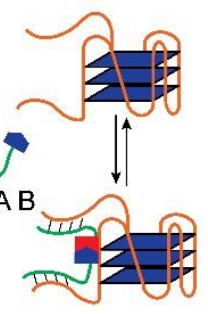

Fluorescent

C
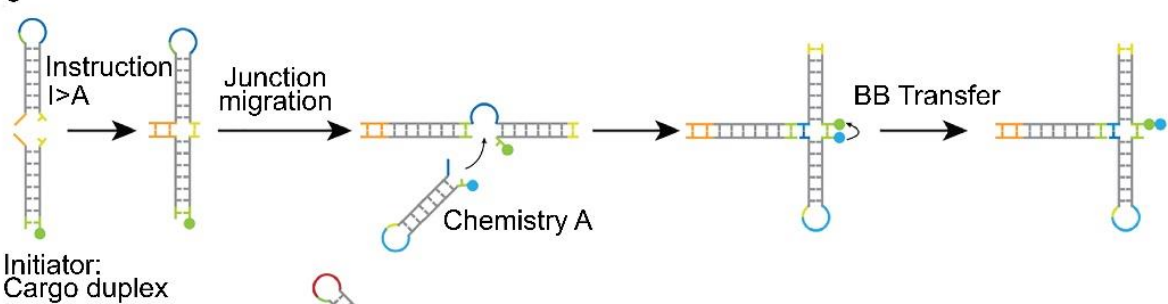

Cargo duplex

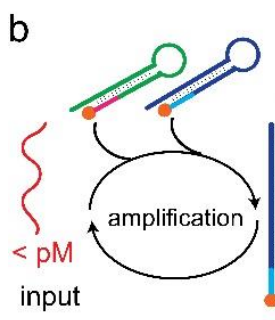

b

Pro-functional
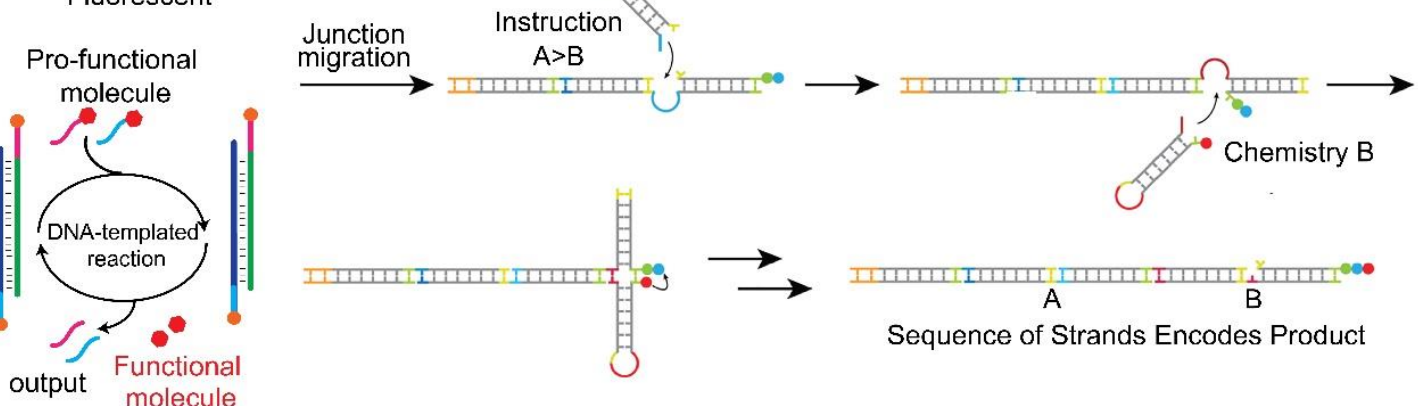

I

A
Sequence of Strands Encodes Product

Figure 2. (a) Fluorogenic templated reaction of cyanine dyes for sensing the formation of DNA G-quadruplex. Two non-fluorescent precursors attached to peptide nucleic acid (PNA) sequences are colocalized by the hybridization of PNA to the flanking arms of a G-quadruplex motif, leading to the formation of a cyanine dye. Adapted with permission from [87]. Copyright (2010) WILEY-VCH Verlag GmbH \& Co. KGaA, Weinheim. (b) Coupling of DNA circuit with templated reactions for signal amplification applied to the formation of functional molecules. Exponential amplification is obtained by the combination of a DNA circuit that responds to minimum amounts of an oligonucleotide input that triggers a templated reaction that leads to product formation, i.e. output, with the capability of turnover. Adapted with permission from [91]. Copyright (2019) American Chemical Society. (c) Autonomous assembler of oligomers directed by DNA instruction strands. A series of DNA hybridization events are coupled to templated group transfer reactions that allow the ligation of specific building blocks to a growing oligomer in a programmed manner encoded in DNA. Adapted with permission from [101]. Copyright (2017) American Chemical Society.

Wissinger and coworkers put into practice this strategy and unleash the function of a variety of molecules via templated Staudinger reactions. ${ }^{[90]}$ Recently, they also coupled DTS with DNA circuits for the release of molecules in response to femtomolar concentrations of nucleic acids, achieving a remarkable sensitivity through multiple rounds of amplification. By tuning the nature of the released functional molecule, so as it acts either as reporter or as a therapeutically active agent, this strategy can be of interest for both sensing and drug release purposes, respectively (Fig. 2b). ${ }^{[91]}$ Furthermore, DTS has been exploited to program the synthesis of complex molecules, such as macrocycles, ${ }^{[92,93]}$ oligomers ${ }^{[94]}$ and non-natural small molecules, ${ }^{[95,96]}$ via multistep reactions in a single pot. Autonomous systems were also developed, such as a mechanical 
arrangement in which a DNA walker triggers reactions as it moves along a nucleic acid track, conceptually mimicking a ribosome. This precise and controllable motion is powered by photon radiation owing to the introduction of photosensitive moieties into the DNA backbone that mediate the cleavage of disulfide bonds upon light exposure, thus triggering the movement. ${ }^{[97]}$. Turberfield, O'Reilly and coworkers reported a self-running assembler of oligomers directed by a cascade of DNA-based reactions; their strategy is easily adaptable to different oligomer sequences just by tuning the DNA-based molecular program (Fig. 2c). ${ }^{[98]}$ This ability to perform higher-order synthesis has spurred research efforts towards the construction of chemical libraries. ${ }^{[99]}$ The wide variety of chemistries available for DTS together with the high encoding capacity of DNA makes this approach a powerful screening technology for molecular discovery; a chemical library containing millions of DNA-tagged molecules can be generated for the subsequent affinity-based selection of compounds of interest. Liu and coworkers recently reported a DNA-templated library of macrocycles containing 256,000 druglike molecules for the discovery of new enzyme inhibitors. ${ }^{[93]}$ Hansen et al. developed a "YoctoReactor", namely a DNA-based device where controlled reactions occur in a confined space at the center of DNA junctions, leading to the synthesis of a library of small molecules. ${ }^{[100]}$ For a comprehensive review of DTS as a tool for the generation of programmable molecular libraries we recommend consulting some dedicated reviews. ${ }^{[81,101]}$

\section{DNA-scaffolded systems to control enzymatic catalysis}

Enzyme reactions are ubiquitous in nature, where multi-enzyme cascades play crucial role in many biological processes, including cell signaling and metabolism. Within the cellular environment, the confinement of enzymatic reactions into specific nanoscale compartments allows to overcome low kinetic rates, regulate cascade reactions and avoid the release of undesirable intermediates that could led to toxic or cross-reaction effects. ${ }^{[102]}$ Taking inspiration from nature, one-dimensional, two-dimensional and three-dimensional DNA constructs have been used to enhance enzyme catalysis. ${ }^{[103-105]}$ One of the pioneering works was carried out by Willner's group, who used programmable hexagonal DNA scaffolds with protruding tethers that allowed to position enzyme and cofactors with controlled separation among them. An effective communication and operation of the Glucose Oxidase and horse radish peroxidase bi-enzyme cascade was observed, being it enhanced by 15 -fold when compared to diffusion-dependent communication. ${ }^{[106]}$ In a simpler yet effective approach, Fu. and coworkers pioneered the use of 2D DNA origami planar scaffolds to control interenzyme separation between glucose oxidase and horse radish peroxidase, where they measured that the optimal distance for the maximum activity of the enzyme pair was $10 \mathrm{~nm}$ (Fig. 3 a). ${ }^{[107]}$ Similar approaches have been used to enhance catalytic reactions of multi-enzyme cascades by improving the effective molar concentration of the $\mathrm{NAD+}$, either by integrating a swinging arm between enzymes ${ }^{[108]}$ or by increasing enzyme proximity in structurally confined holes in origami tiles, where the NAD+ could be re-used in a $\mathrm{NAD+} / \mathrm{NADH}$-cofactor-coupled mediated bienzyme cascades. ${ }^{[109]}$ The active formation of nanoholes in the origami scaffolds and the subsequent programmed and switchable catalysis in the resulting cavities can also be achieved employing DNAzymes or light as triggers. ${ }^{[110]} A$ different approach to control enzyme activation has been recently reported by de Greef's group, where the activation of a synthetic caspase- 9 based apoptosome was triggered by the proximity of different monomers, precisely positioned using $2 \mathrm{D}$ DNA scaffolds (Fig. 3b). ${ }^{[111,112]}$ a

C

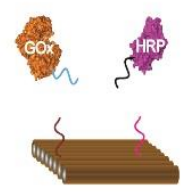

DNA origami tile

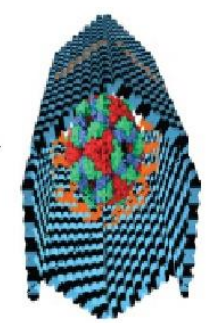

b
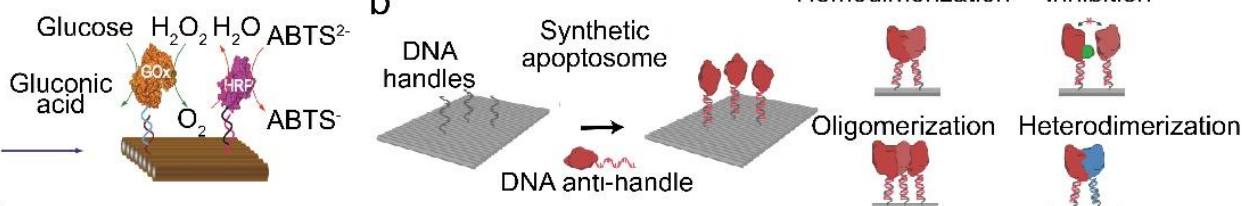

d
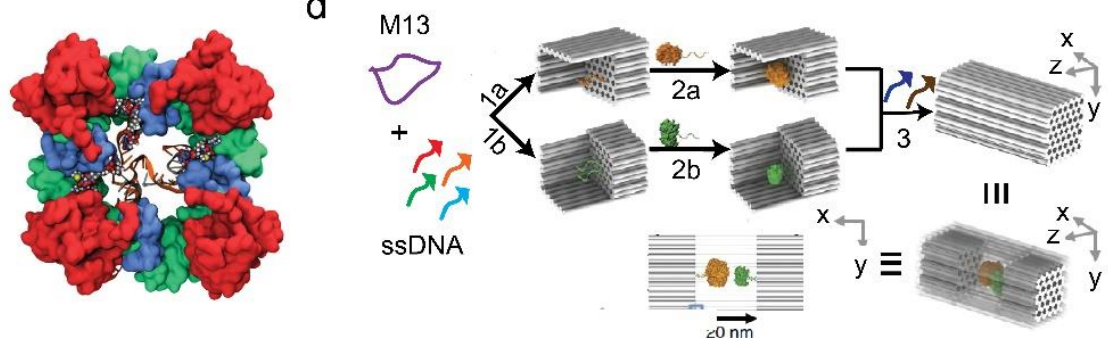

Figure 3. (a) $\mathrm{GO}_{x}$ and $\mathrm{HRP}$ cascade reaction enhancement by controlling their proximity in a 2D DNA origami sheet. Adapted with permission from [108]. Copyright (2012) American Chemical Society. (b) Generation of a synthetic apoptosome by controlling the proximity between different caspase-9 sub units on a 2D DNA origami. Adapted with permission of the authors from [111] .(c) Enzyme encapsulation into a 3D DNA origami tubular structure using supramolecular interactions based on host-guest protein based interactions. Adapted with permission from ref [114]. Copyright (2017) Springer Nature. (d) Enzymes encapsulated in multilayered DNA nanocages for improved turnover of both individual enzymes and bienzyme cascades. The nanocages provide also protection from the degradation by external proteases. Adapted with permission from [115]. Copyright (2016) Springer Nature.

On a scaling level of complexity, 3D assembled structures have been employed for enzyme confinement. For instance, Linko and co-workers developed an extendable DNA origami tubular nanoreactor, where the encapsulation of GOx and HRP attached to the inner walls of the tube resulted in a 12-fold increase of activity. ${ }^{[113]}$ In following studies, different strategies for the 
confinement of enzymes have been reported. For instance, Saccà and co-workers used a supramolecular approach to symmetrically decorate the inner walls of a tubular DNA origami nanostructure with specific protein binding ligands that mimic naturally ocurring host-guest complex interactions and avoiding typical DNA-protein conjugation chemistry (Fig. 3c). However, this strategy is limited to the type of protein that can be conjugated might hinder the translation it into different types of enzymes. ${ }^{[114]}$ Alternatively, Yan et al. reported the use of lysine-binding chemical strategy to fully encapsulate active enzymes within a multi-layered DNA nanocage (Fig. 3d). In this study the authors described an increased turnover rate for individual enzymes as well as bienzyme cascades. ${ }^{[15]}$ Interestingly, an inversed correlation between enzyme activity and protein size was observed, which was attributed to the stabilizing effect by negatively charged DNA surfaces. Later studies suggested that the affinity of substrates for the DNA template as well as intermolecular interactions could be the underlying source for this effect. ${ }^{[16,117]}$ These observations led to a current debate on the actual mechanism underlying DNA enhancement of enzyme activity. In this regard, the catalytic enhancement by DNA scaffolds was initially attributed to proximity effects, including a facilitated transport or substrate channeling. ${ }^{[118,119]}$ However, recent studies point out at other effects rather than proximity as the underlying mechanism of DNA-enhanced enzyme activity, including a lowering of the local $\mathrm{pH}$ by the highly negatively charged DNA, ${ }^{[120,121]}$ increased enzyme stability, localized DNA surface affinity or hydration layer effects. ${ }^{[122]}$

Taken together, these results indicate that depending on the application and interest of the study, different DNA scaffolds can be designed. While 2D scaffolds allow for a more precise location and easier identification of enzyme positioning, 3D scaffolds might constitute a better option when protection of enzymes, for instance from external proteases, is required. Regardless of the mechanism of actuation and designed structures, DNA scaffolds have so far shown to increase enzyme catalysis in all the reported studies, holding a great potential for the spatial regulation and confinement as useful tools to enhance catalytic activity and controlled cascade reactions.

\section{Conclusions}

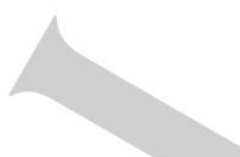

The spatial colocalization and confinement at the nanoscale of functional biomolecules in natural systems are widespread mechanisms that regulates a number of cell activities. This, alongside recent progresses in DNA nanotechnology, represents a source of inspiration for the design of artificial, nucleic acidbased systems with programmable properties. In this article, we highlighted how effective molarity-driven processes induced by biomolecular confinement can be engineered and applied to synthetic DNA-based systems. In particular, we aimed to report recent trends in the fields of templated organic chemistry, catalysis, biosensing and supramolecular assembly. The many examples we have reported herein set forth how mimicking naturally occurring mechanisms to control programmable DNAbased systems is likely to lay the foundation of a multitude of novel biomimetic synthetic processes with broad applications in chemistry and biology.

\section{Acknowledgements}

A.P. received support from the University of Rome Tor Vergata under the grant "MIRA" no E81/18000200005. This project has received funding from the European Union's Horizon 2020 research and innovation programme under the Marie Skłodowska-Curie grant agreement Nano-Oligo Med No 778133 M.R. and A.B. are supported from a Fondazione Umberto Veronesi fellowship. T.P. is a Marie Sklodowska-Curie Fellow (grant agreement No 843998). L.B. is an Early Stage Researcher (ESR) under the Marie Skłodowska-Curie ITN project "DNARobotics" (grant agreement No 765703).

Keywords: DNA nanotechnology $\cdot$ effective molarity • proximity assays $\cdot$ DNA-templated chemistry $\bullet$ Synthetic biology

[1] S. Nummelin, J. Kommeri, M. A. Kostiainen, V. Linko, Adv. Mater 2018, 30, 1703721 .

[2] N. C. Seeman, H. F. Sleiman, Nat. Rev. Mater. 2017, 3, 1-23.

[3] Y. Ke, C. Castro, J. H. Choi, Annu. Rev. Biomed. Eng. 2018, 20 , 375-401.

[4] F. Zhang, J. Nangreave, Y. Liu, H. Yan, J. Am. Chem. Soc. 2014, 136, 11198-11211

[5] L. N. Green, H. K. K. Subramanian, V. Mardanlou, J. Kim, R. F. Hariadi, E. Franco, Nat. Chem. 2019, 11, 510-520.

[6] L. Yue, S. Wang, A. Cecconello, J. M. Lehn, I. Willner, ACS Nano 2017, 11, 12027-12036.

[7] Y. Yu, B. Jin, Y. Li, Z. Deng, Chem. - A Eur. J. 2019, 25, 97859798.

[8] M. Rossetti, A. Porchetta, Anal. Chim. Acta 2018, 1012, 30-41. [9] J. S. Kahn, Y. Hu, I. Willner, Acc. Chem. Res. 2017, 50, 680-690.

[10] Y. Li, L. Song, B. Wang, J. He, Y. Li, Z. Deng, C. Mao, Angew. Chem. Int. Ed. 2018, 130, 7008-7011.

[11] C. Zhou, X. Duan, N. Liu, Acc. Chem. Res. 2017, 50, 2906-2914.

[12] S. D. Mason, Y. Tang, Y. Li, X. Xie, F. Li, TrAC - Trends Anal. Chem. 2018, 107, 212-221.

[13] X. Mao, A. J. Simon, H. Pei, J. Shi, J. Li, Q. Huang, K. W. Plaxco, C Fan, Chem. Sci. 2016, 7, 1200-1204.

[14] S. Kotani, W. L. Hughes, J. Am. Chem. Soc. 2017, 139, 6363-6368.

[15] F. Wang, H. Lv, Q. Li, J. Li, X. Zhang, J. Shi, L. Wang, C. Fan, Nat. Commun. 2020, 11, 1-8.

[16] J. Elbaz, O. Lioubashevski, F. Wang, F. Remacle, R. D. Levine, I. Willner, Nat. Nanotechnol. 2010, 5, 417-422.

[17] G. Chatterjee, N. Dalchau, R. A. Muscat, A. Phillips, G. Seelig, Nat. Nanotechnol. 2017, 12, 920-927.

[18] A. Vallée-Bélisle, F. Ricci, T. Uzawa, F. Xia, K. W. Plaxco, J. Am. Chem. Soc. 2012, 134, 15197-15200

[19] A. Idili, K. W. Plaxco, A. Vallée-Bélisle, F. Ricci, ACS Nano 2013, 7, 10863-10869.

[20] F. Wang, X. Liu, I. Willner, Angew. Chem. Int. Ed. 2015, 54, 10981129.

[21] S. G. Harroun, C. Prévost-Tremblay, D. Lauzon, A. Desrosiers, X. Wang, L. Pedro, A. Vallée-Bélisle, Nanoscale 2018, 10, 4607-4641.

[22] Y. Zhao, F. Chen, Q. Li, L. Wang, C. Fan, Chem. Rev. 2015, 115, 12491-12545. 
D. Wilhelm, J. Bruck, L. Qian, Proc. Natl. Acad. Sci. U. S. A. 2018 115, 903-908.

[25] H. Wang, H. Wang, I. Willner, F. Wang, Top. Curr. Chem. 2020, 378, 1-32.

[26] N. Srinivas, J. Parkin, G. Seelig, E. Winfree, D. Soloveichik, Science 2017, 358, eaal2052.

[27] D. Scalise, R. Schulman, Annu. Rev. Biomed. Eng. 2019, 21, 469493.

[28] S. F. J. Wickham, J. Bath, Y. Katsuda, M. Endo, K. Hidaka, H. Sugiyama, A. J. Turberfield, Nat. Nanotechnol. 2012, 7, 169-173. C. Baek, S. W. Lee, B. J. Lee, D. H. Kwak, B. T. Zhang, Molecules 2019, 24, 1409.

Y. Lyu, C. Wu, C. Heinke, D. Han, R. Cai, I. T. Teng, Y. Liu, H. Liu, X. Zhang, Q. Liu, et al., J. Am. Chem. Soc. 2018, 140, 6912-6920. A. Joesaar, S. Yang, B. Bögels, A. van der Linden, P. Pieters, B. V. V. S. P. Kumar, N. Dalchau, A. Phillips, S. Mann, T. F. A. de Greef, Nat. Nanotechnol. 2019, 14, 369-378.

J. Tyson, S. Kauffman, J. Math. Biol. 1975, 1, 289-310.

P. Guemkam Ghomsi, F. M. Moukam Kakmeni, T. C. Kofane, C. Tchawoua, Phys. Lett. Sect. A 2014, 378, 2813-2823.

A. H. Chen, P. A. Silver, Trends Cell Biol. 2012, 22, 662-670. R. J. Conrado, T. J. Mansell, J. D. Varner, M. P. DeLisa, Metab. Eng. 2007, 9, 355-363.

S. F. Banani, H. O. Lee, A. A. Hyman, M. K. Rosen, Nat. Rev. Mol. Cell Biol. 2017, 18, 285-298.

S. An, R. Kumar, E. D. Sheets, S. J. Benkovic, Science 2008, 320, 103-106.

L. Mandolini, Adv. Phys. Org. Chem. 1986, 22, 1-111.

M. I. Page, W. P. Jencks, Proc. Natl. Acad. Sci. U. S. A. 1971, 68, 1678-1683.

B. Z. Stanton, E. J. Chory, G. R. Crabtree, Science 2018, 359, eaao5902.

J. Kuriyan, D. Eisenberg, Nature 2007, 450, 983-990.

H. Zhang, F. Li, B. Dever, C. Wang, X.-F. Li, X. C. Le, Angew. Chem. Int. Ed. 2013, 52, 10698-10705.

S. Fredriksson, M. Gullberg, J. Jarvius, C. Olsson, K. Pietras, S. M. Gústafsdóttir, A. Östman, U. Landegren, Nat. Biotechnol. 2002, 20 , 473-477.

O. Söderberg, M. Gullberg, M. Jarvius, K. Ridderstråle, K. J. Leuchowius, J. Jarvius, K. Wester, P. Hydbring, F. Bahram, L. G. Larsson, et al., Nat. Methods 2006, 3, 995-1000.

W. Wu, Z. Yan, T. C. Nguyen, Z. Bouman Chen, S. Chien, S. Zhong, Nat. Protoc. 2019, 14, 3243-3272.

R. Y. Nong, D. Wu, J. Yan, M. Hammond, G. J. Gu, M. KamaliMoghaddam, U. Landegren, S. Darmanis, Nat. Protoc. 2013, 8 , 1234-1248.

C. Greenwood, D. Ruff, S. Kirvell, G. Johnson, H. S. Dhillon, S. A. Bustin, Biomol. Detect. Quantif. 2015, 4, 10-16.

S. Fredriksson, W. Dixon, H. Ji, A. C. Koong, M. Mindrinos, R. W. Davis, Nat. Methods 2007, 4, 327-329.

F. Li, H. Zhang, Z. Wang, X. Li, X. F. Li, X. C. Le, J. Am. Chem. Soc. 2013, 135, 2443-2446.

F. Li, Y. Tang, S. M. Traynor, X.-F. Li, X. C. Le, Anal. Chem. 2016 88, 8152-8157.

[51] L. Zhang, K. Zhang, G. Liu, M. Liu, Y. Liu, J. Li, Anal. Chem. 2015, $87,5677-5682$.
[52]

[53]

[54]

[55]

[56]

[57]

[58]

[59]

[60]

[61]

[63]
B. Deng, J. Chen, H. Zhang, Anal. Chem. 2014, 86, 7009-7016. F. Li, Y. Lin, X. C. Le, Anal. Chem. 2013, 85, 10835-10841. Y. Tang, Y. Lin, X. Yang, Z. Wang, X. C. Le, F. Li, Anal. Chem. 2015, 87, 8063-8066.

Y. S. Ang, L. Y. L. Yung, Nucleic Acids Res. 2014, 42, 9523-9530. H. Liang, S. Chen, P. Li, L. Wang, J. Le, J. Li, H. H. Yang, W. Tan, J. Am. Chem. Soc. 2018, 140, 4186-4190.

Y. S. Ang, J. J. Li, P.-J. Chua, C.-T. Ng, B.-H. Bay, L.-Y. L. Yung, Anal. Chem. 2018, 90, 6193-6198.

Y. Tang, Z. Wang, X. Yang, J. Chen, L. Liu, W. Zhao, X. C. Le, F. Li, Chem. Sci. 2015, 6, 5729-5733.

W. Engelen, S. P. W. Wijnands, M. Merkx, J. Am. Chem. Soc. 2018, 140, 9758-9767.

R. Luedtke, C. S. Owen, F. Karush, Biochemistry 1980, 19, 1182 1192.

T. J. Smith, N. H. Olson, R. H. Cheng, E. S. Chase, T. S. Baker, Proc. Natl. Acad. Sci. U. S. A. 1993, 90, 7015-7018.

X. Zhang, L. Zhang, H. Tong, B. Peng, M. J. Rames, S. Zhang, G. Ren, Sci. Rep. 2015, 5, 9803.

H. Zhang, F. Li, B. Dever, C. Wang, X.-F. Li, X. C. Le, Angew. Chem. Int. Ed. 2013, 52, 10698-10705.

B. M. G. Janssen, E. H. M. Lempens, L. L. C. Olijve, I. K. Voets, J. L. J. van Dongen, T. F. A. de Greef, M. Merkx, Chem. Sci. 2013, 4, 1442-1450.

L. Tian, T. Heyduk, Anal. Chem. 2009, 81, 5218-5225.

X. Yan, X. C. Le, H. Zhang, Anal. Chem. 2018, 90, 9667-9672. A. Porchetta, R. Ippodrino, B. Marini, A. Caruso, F. Caccuri, F. Ricci, J. Am. Chem. Soc. 2018, 140, 947-953.

M. Rossetti, R. Ippodrino, B. Marini, G. Palleschi, A. Porchetta, Anal. Chem. 2018, 90, 8196-8201.

A. Bertucci, A. Porchetta, F. Ricci, Anal. Chem. 2018, 90, 10491053.

N. Li, L. Liu, M. H. Xiang, J. W. Liu, R. Q. Yu, J. H. Jiang, Chem. Commun. 2019, 55, 4387-4390.

W. Engelen, L. H. H. Meijer, B. Somers, T. F. A. De Greef, M. Merkx, Nat. Commun. 2017, 8, 1-8:1447.

S. Ranallo, D. Sorrentino, F. Ricci, Nat. Commun. 2019, 10, 1-9: 5509.

H. Araki, in DNA Replication, Recomb. Repair Mol. Mech. Pathol., Springer Japan, 2016, pp. 3-22.

C. B. Rosen, T. Tørring, K. V. Gothelf, Nucleic Acid Nanotechnology, Springer, Berlin, 2014, 173-197.

R. Naylor, P. T. Gilham, Biochemistry 1966, 5, 2722-2728.

R. Lohrmann, L. E. Orgel, Nature 1976, 261, 342-344.

X. Li, D. R. Liu, Angew. Chem. Int. Ed. 2004, 43, 4848-4870.

A. Shibata, H. Abe, Y. Ito, Molecules 2012, 17, 2446-2463.

M. Di Pisa, O. Seitz, ChemMedChem 2017, 12, 872-882.

K. Gorska, N. Winssinger, Angew. Chem. Int. Ed. 2013, 52, 68206843.

N. Favalli, G. Bassi, J. Scheuermann, D. Neri, FEBS Lett. 2018, 592, 2168-2180.

L. H. Yuen, R. M. Franzini, ChemBioChem 2017, 18, 829-836. M. K. Herrlein, R. L. Letsinger, Nucleic Acids Res. 1994, 22, 5076 5078.

J. Michaelis, G. J. Van Der Heden Van Noort, O. Seitz, Bioconjug. Chem. 2014, 25, 18-23.

D. Al Sulaiman, J. Y. H. Chang, S. Ladame, Angew. Chem. Int. Ed. 


\section{7, 129, 5331-5335.}

$[86]$

G. A. D. Metcalf, A. Shibakawa, H. Patel, A. Sita-Lumsden, A. Zivi, N. Rama, C. L. Bevan, S. Ladame, Anal. Chem. 2016, 88, 80918098.

[87] K. Meguellati, G. Koripelly, S. Ladame, Angew. Chem. Int. Ed. 2010, 49, 2738-2742.

[88] L. Holtzer, I. Oleinich, M. Anzola, E. Lindberg, K. K. Sadhu, M. Gonzalez-Gaitan, N. Winssinger, ACS Cent. Sci. 2016, 2, 394-400.

[89] W. A. Velema, E. T. Kool, J. Am. Chem. Soc. 2017, 139, 54055411.

[90] K. Gorska, A. Manicardi, S. Barluenga, N. Winssinger, Chem. Commun. 2011, 47, 4364-4366.

[91] K. T. Kim, S. Angerani, D. Chang, N. Winssinger, J. Am. Chem. Soc. 2019, 141, 16288-16295.

[92] P. J. Milnes, M. L. McKee, J. Bath, L. Song, E. Stulz, A. J. Turberfield, R. K. O'Reilly, Chem. Commun. 2012, 48, 5614-5616.

[93] D. L. Usanov, A. I. Chan, J. P. Maianti, D. R. Liu, Nat. Chem. 2018, 10, 704-714.

[94] M. L. McKee, P. J. Milnes, J. Bath, E. Stulz, R. K. O'Reilly, A. J. Turberfield, J. Am. Chem. Soc. 2012, 134, 1446-1449.

[95] C. Cao, P. Zhao, Z. Li, Z. Chen, Y. Huang, Y. Bai, X. Li, Chem. Commun. 2014, 50, 10997-10999.

[96] P. Blakskjaer, T. Heitner, N. J. V. Hansen, Curr. Opin. Chem. Biol. 2015, 26, 62-71.

[97] Y. He, D. R. Liu, Nat. Nanotechnol. 2010, 5, 778-782.

[98] W. Meng, R. A. Muscat, M. L. McKee, P. J. Milnes, A. H. ElSagheer, J. Bath, B. G. Davis, T. Brown, R. K. O'Reilly, A. J. Turberfield, Nat. Chem. 2016, 8, 542-548.

[99] R. A. Goodnow, C. E. Dumelin, A. D. Keefe, Nat. Rev. Drug Discov. 2017, 16, 131-147.

[100] M. H. Hansen, P. Blakskjaer, L. K. Petersen, T. H. Hansen, J. W Højfeldt, K. V. Gothelf, N. Jakob, V. Hansen, J. Am. Chem. Soc. 2009, 131, 1322-1327.

[101] R. K. O'Reilly, A. J. Turberfield, T. R. Wilks, Acc. Chem. Res. 2017, 50, 2496-2509.

[102] A. Küchler, M. Yoshimoto, S. Luginbühl, F. Mavelli, P. Walde, Nat. Nanotechnol. 2016, 11, 409-420.

[103] M. Vázquez-González, C. Wang, I. Willner, Nat. Catal. 2020, 3, 256-273.

[104] Jaekel, Stegemann, Saccà, Molecules 2019, 24, 3694.

[105] S. Ranallo, A. Porchetta, F. Ricci, Anal. Chem. 2019, 91, 44-59.

[106] O. I. Wilner, Y. Weizmann, R. Gill, O. Lioubashevski, R. Freeman, I. Willner, Nat. Nanotechnol. 2009, 4, 249-254.

[107] J. Fu, M. Liu, Y. Liu, N. W. Woodbury, H. Yan, J. Am. Chem. Soc. 2012, 134, 5516-5519.

[108] J. Fu, Y. R. Yang, A. Johnson-Buck, M. Liu, Y. Liu, N. G. Walter, N. W. Woodbury, H. Yan, Nat. Nanotechnol. 2014, 9, 531-536.

[109] T. A. Ngo, E. Nakata, M. Saimura, T. Morii, J. Am. Chem. Soc. 2016, 138, 3012-3021.

[110] J. Wang, L. Yue, Z. Li, J. Zhang, H. Tian, I. Willner, Nat. Commun. 2019, 10, 1-10.

[111] B. J. H. M. Rosier, A. J. Markvoort, B. Gumí Audenis, J. A. L. Roodhuizen, A. den Hamer, L. Brunsveld, T. F. A. de Greef, Nat. Catal. 2020, 3, 295-306.

[112] B. J. H. M. Rosier, A. J. Markvoort, B. Gumí-Audenis, J. A. L. Roodhuizen, A. den Hamer, L. Brunsveld, T. F. A. de Greef, bioRxiv 2019, 660183 .
[113] V. Linko, M. Eerikäinen, M. A. Kostiainen, Chem. Commun. 2015, 51, 5351-5354.

[114] A. Sprengel, P. Lill, P. Stegemann, K. Bravo-Rodriguez, E.-C. Schöneweiß, M. Merdanovic, D. Gudnason, M. Aznauryan, L. Gamrad, S. Barcikowski, et al., Nat. Commun. 2017, 8, 14472.

[115] Z. Zhao, J. Fu, S. Dhakal, A. Johnson-Buck, M. Liu, T. Zhang, N. W. Woodbury, Y. Liu, N. G. Walter, H. Yan, Nat. Commun. 2016, 7, 10619.

[116] C. Timm, C. M. Niemeyer, Angew. Chem. Int. Ed. 2015, 54, 67456750.

[117] Y. Zhang, J. Ge, Z. Liu, ACS Catal. 2015, 5, 4503-4513.

[118] I. Wheeldon, S. D. Minteer, S. Banta, S. C. Barton, P. Atanassov, M. Sigman, Nat. Chem. 2016, 8, 299-309.

[119] O. Idan, H. Hess, ACS Nano 2013, 7, 8658-8665.

[120] Y. Zhang, S. Tsitkov, H. Hess, Nat. Commun. 2016, 7, 13982.

[121] Y. Zhang, H. Hess, ACS Catal. 2017, 7, 6018-6027.

[122] W. P. Klein, R. P. Thomsen, K. B. Turner, S. A. Walper, J. Vranish, J. Kjems, M. G. Ancona, I. L. Medintz, ACS Nano 2019, 13, 1367713689 


\section{Entry for the Table of Contents}

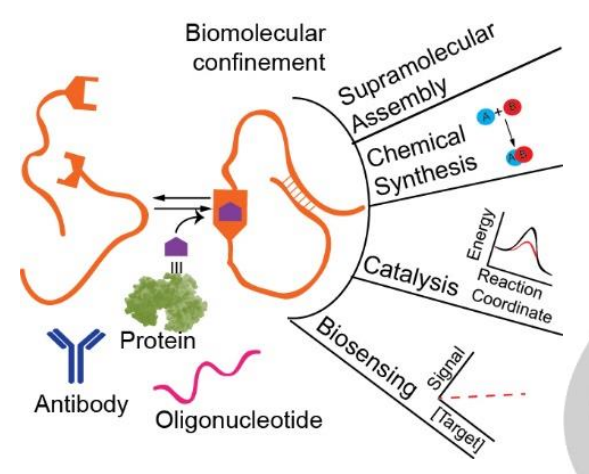

Inspired by Nature that employs spatial confinement of biomolecules to regulate biological functions, scientists have artificially reproduced effective molarity-driven processes and applied it to DNA nanotechnology. In this minireview, we highlight and discuss the use of biomolecular confinement and effective molarity as strategies to program and assemble functional DNA-based systems. 